\title{
Molecular Structure and Quantum Chemical Calculations of 2, 4-difluoroanisole
}

\author{
S. Jeyavijayan, Palani Murugan, M. S. Revathy, K. Gurushankar, K. Viswanathan
}

\begin{abstract}
FTIR / FT-Raman spectra in the regions 4000-400 $\mathrm{cm}^{-1} / 3500-50 \mathrm{~cm}^{-1}$ are utilized for studying the molecular vibrations of 2,4-difluoroanisole (DFA). The optimized molecular structure and vibrational analysis of the DFA were estimated with the experimental as well as quantum chemical studies from ab initio and DFT calculations. The chemical shifts of ${ }^{1} \mathrm{H}$ and ${ }^{13} \mathrm{C}$ NMR were calculated. In addition, the thermodynamic and important electronic properties like HOMO-LUMO, NPA charge analyses have been examined. With the aid of NBO (Natural Bond Orbital) analysis, inter and intra molecular interactions are also illustrated.
\end{abstract}

Keywords: 2,4-difluoroanisole, FTIR, FT-Raman, NMR, ab initio, B3LYP.

\section{INTRODUCTION}

Among the aromatic compounds, anisole possess simple structure with ether group. Being a synthetically processed material, it is usually a precursor for the formulation of new compounds. Anisole is a notable insect repellent and a part of Cresol type antiseptic compounds. In modern days, their derivatives are used as solvents, perfumery and extensive incorporation as intermediates in chemical reaction to acquire target materials such as agrochemicals, pharmaceuticals, perfumes, dyes and photo initiators. The orientation of methyl group in anisole was found to be important in governing the pharmacological propertiesof drugs. These interesting features of anisole and their derivatives have led to wide variety of research including spectroscopic investigations [1-4]. Hence, the vibrational spectroscopic literature on fluoro anisole derivatives motivated us to venture into the spectroscopic investigation on the title compound, namely, 2,4-difluoroanisole (DFA).

The present study seeks to portray the vibrational analysis of DFA by means of quantum mechanical method based on the $a b$ initio HF/DFT calculations. Further, the ground state optimized geometries and the charge

Revised Manuscript Received on December 29, 2019.

* Correspondence Author

S. Jeyavijayan*, Department of Physics , Kalasalingam Academy of Research and Education, Krishnankoil-626 126, Tamil Nadu, India Email : sjeyavijayan@gmail.com

Palani Murugan, Department of Physics, Dr. B.R. Ambedkar Institute of Technology, Port Blair-744103, Andaman \& Nicobar Islands, India Email : palanimuruganviji@gmail.com

M.S.Revathy, Department of Physics, Kalasalingam Academy of Research and Education, Krishnankoil-626 126,Tamil Nadu, India Email : revz.vijay@gmail.com

K. Gurushankar, Department of Physics, Kalasalingam Academy of Research and Education, Krishnankoil-626 126, Tamil Nadu, India Email : kgurumsc@yahoo.com

K. Viswanathan, Department of Physics, Kalasalingam Academy of Research and Education, Krishnankoil-626 126, Tamil Nadu, India Email : kvnooty@gmail.com distribution associated with different atoms for DFA have been analyzed.The performance of the computational method for $a b$ initio HF and DFT-B3LYP are compared.These methods predict relatively accurate molecular structure and vibrational spectra with moderate computational effort.

\section{MATERIAL AND METHODOLOGY}

DFA, a fine polycrystalline specimen (98\% purity) was procured commercially and utilized without extra purification. Spectroscopic tools such as room temperature FTIR(Fourier transform infrared spectra) by JASCO FTIR 6300 spectrometer in recording range $4000-400 \mathrm{~cm}^{-1}$ of $\pm 1 \mathrm{~cm}^{-1}$ resolution and FT-Raman spectrum by BRUKER RFS 100/S model interferometer equipped with accessory FRA-106 FT-Raman in $3500-50 \mathrm{~cm}^{-1}$ range for the title compound was utilized and recorded.

\section{COMPUTATION AND SIMULATION}

In order to attain the complete geometry optimization, assessment was done through $a b$ initio and density functional theoretical computations by Gaussian 09 program[5]. Hartree-Fock (HF) and DFT/B3LYP functionally [6] combined with the standard 6-311++G(d,p) basis set, was executed to look for the activities of IR, Raman and molecular global minimum energy in DFA. Initial geometry made from the standard geometrical parameters was minimized without any constraint on the potential energy surface at Hartree-Fock level adopting the standard 6-311++G(d,p) basis set. This geometry was then re-optimized at DFT level employing the B3LYP method [7] with the same basis set for better description of the bonding properties. All the parameters were allowed to relax and all the calculations converged to an optimized geometry which corresponds to a true minimum and the absence of the imaginary frequencies are guaranteed. The Cartesian representation of the theoretical force constants have been computed at the fully optimized geometry. Scaled quantum mechanical (SQM) procedure [8] has been followed for better agreement between computational and the experimental data. The MOLVIB Program (Version V7.0-G77) by Sundius [9] has been used for the calculation of the PED (potential energy distribution). 


\section{RESULT AND DISCUSSION}

\section{A. Molecular Geometry}

In Fig.1, the molecular structure of DFA with numbering of atoms is shown. The values -545.42274825 and -545.39552894 Hartrees correspond to the global minimal energies acquired by $a b$ initio $\mathrm{HF}$ and DFT/B3LYP with $6-311++G(d, p)$ basis set, respectively. The optimized geometrical parameters of DFA obtained by using the above methods are presented along with the experimental data of similar structures $[10,11]$ in TableI. It is notified that the geometrical parameters computed by B3LYP method establish to be closer with the experimental ones. With the help of $a b$ initio HF as well as DFT-B3LYP levels using 6-311++G(d,p) basis set, the thermodynamic properties like heat capacity, entropy, rotational constants, dipole moment and zero point vibrational energy (ZPVE) have been computed and the results are presented in Table II.

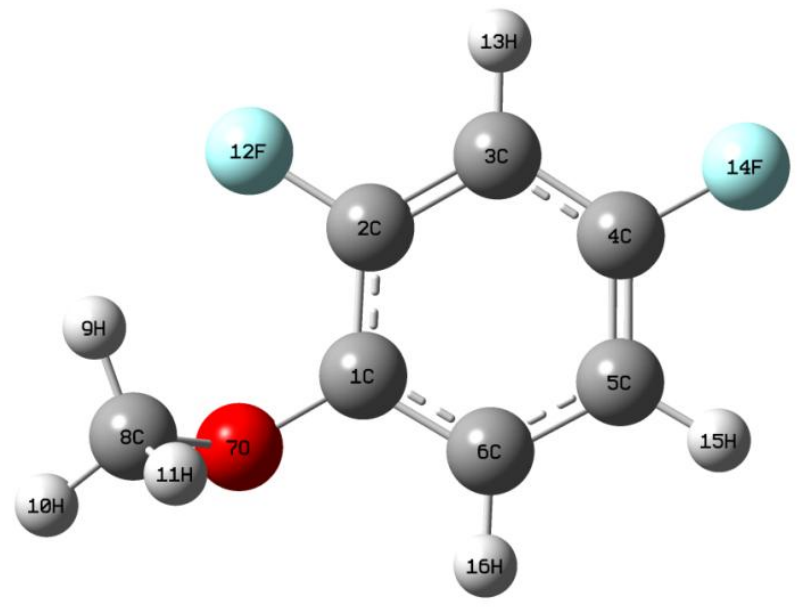

Figure 1. Molecular structure of 2,4-difluoroanisole

\section{B. Vibrational Analysis}

The molecule under investigation contains 16 atoms and therefore it has 42 modes (i.e)., $(3 \mathrm{~N}-6)$ of vibrations. The geometry of DFA is considered to have $C_{s}$ point group symmetry. The 42 normal modes in DFA are disseminated amongst the symmetry species as,

$$
\Gamma_{\mathrm{DFA}}=28 \mathrm{~A}^{\prime} \text { (in-plane) }+14 \mathrm{~A}^{\prime \prime} \text { (out-of-plane). }
$$

The experimental FTIR/FT-Raman spectra of DFA are revealed in Fig. 2. The detailed vibrational assignment along with calculated results is given in Table III.

Due to the electron correlation approximaticity, the anharmonicity effect and basis set deficiency, the frequencies of vibration attained by quantum chemical calculations with unscaled $a b$ initio and DFT force fields are generally greater compared with experimental values [12]. Therefore, scaling is done to enhance the agreement between computed and experimental frequencies. After scaling, the theoretical frequencies are correlated and matched well with the experimental ones.

\section{C-H Vibrations}

The C-H stretching vibrations are normally found between 3100 and $3000 \mathrm{~cm}^{-1}$ [13]. The bands observed at $3087,3084,3013 \mathrm{~cm}^{-1}$ and computed at 3099, 3095, 3029 $\mathrm{cm}^{-1}$ and 3093, 3088, 3016 with $100 \%$ PED, by HF and B3LYP methods, respectively, in DFA have been assigned to $\mathrm{C}-\mathrm{H}$ stretching mode of vibrations. Substitution sensitive $\mathrm{C}-\mathrm{H}$ in-plane bending vibrations lie in the region $1000-1300 \mathrm{~cm}^{-1}$ [14]. Bands observed at 1183, 1031, 955 $\mathrm{cm}^{-1}$ and calculated bands (HF method) at 1196, 1052, 971 $\mathrm{cm}^{-1}$ with almost $70 \%$ of PED are allocated to C-H in-plane bending mode of vibrations. Bands linking the out-of-plane $\mathrm{C}-\mathrm{H}$ vibrations appear in the range $1000-675 \mathrm{~cm}^{-1}$. Bands of $872,810,769$ and $865,804,759 \mathrm{~cm}^{-1}$ by HF and B3LYP methods and the IR bands observed at 862,801 and $754 \mathrm{~cm}^{-1}$ in DFA are attributed to C-H (out-of-plane) bending mode of vibrations.

Table I. Experimental (XRD) and optimized geometrical parameters of 2,4-difluoroanisole

\begin{tabular}{|c|c|c|c|}
\hline Parameters & $\operatorname{Expt}^{10,11}$ & $\mathrm{HF}$ & B3LYP \\
\hline \multicolumn{4}{|c|}{ Bond length $\left(\mathrm{A}^{\mathrm{o}}\right)$} \\
\hline $\mathrm{C} 1-\mathrm{C} 2$ & 1.407 & 1.385 & 1.400 \\
\hline $\mathrm{C} 1-\mathrm{C} 6$ & 1.399 & 1.383 & 1.395 \\
\hline $\mathrm{C} 1-\mathrm{O} 7$ & 1.359 & 1.352 & 1.367 \\
\hline $\mathrm{C} 2-\mathrm{C} 3$ & 1.373 & 1.376 & 1.385 \\
\hline $\mathrm{C} 2-\mathrm{F} 12$ & 1.350 & 1.322 & 1.353 \\
\hline $\mathrm{C} 3-\mathrm{C} 4$ & 1.393 & 1.377 & 1.387 \\
\hline $\mathrm{C} 3-\mathrm{H} 13$ & 1.085 & 1.073 & 1.082 \\
\hline $\mathrm{C} 4-\mathrm{C} 5$ & 1.387 & 1.375 & 1.385 \\
\hline $\mathrm{C} 4-\mathrm{F} 14$ & 1.351 & 1.325 & 1.354 \\
\hline C5-C6 & 1.385 & 1.386 & 1.393 \\
\hline C5-H15 & 1.085 & 1.073 & 1.082 \\
\hline C6-H16 & 1.085 & 1.075 & 1.083 \\
\hline $\mathrm{O} 7-\mathrm{C} 8$ & 1.427 & 1.411 & 1.436 \\
\hline C8-H9 & 1.089 & 1.080 & 1.092 \\
\hline C $8-\mathrm{H} 10$ & 1.089 & 1.080 & 1.089 \\
\hline C8-H11 & 1.089 & 1.086 & 1.095 \\
\hline \multicolumn{4}{|l|}{ Bond angle $\left({ }^{\circ}\right)$} \\
\hline $\mathrm{C} 1-\mathrm{C} 2-\mathrm{C} 3$ & 123.5 & 122.34 & 122.46 \\
\hline $\mathrm{C} 2-\mathrm{C} 3-\mathrm{C} 4$ & 116.0 & 117.74 & 117.67 \\
\hline $\mathrm{C} 3-\mathrm{C} 4-\mathrm{C} 5$ & 123.6 & 122.24 & 122.32 \\
\hline C4-C5-C6 & 118.5 & 118.45 & 118.47 \\
\hline $\mathrm{C} 1-\mathrm{C} 6-\mathrm{C} 5$ & 120.2 & 121.27 & 121.40 \\
\hline $\mathrm{C} 2-\mathrm{C} 1-\mathrm{C} 6$ & 118.1 & 117.96 & 117.66 \\
\hline $\mathrm{C} 2-\mathrm{C} 1-\mathrm{O} 7$ & 124.9 & 121.27 & 122.80 \\
\hline $\mathrm{C} 1-\mathrm{C} 2-\mathrm{F} 12$ & 118.5 & 118.99 & 119.14 \\
\hline C3-C2-F12 & 118.5 & 118.66 & 118.39 \\
\hline C3-C4-F14 & 118.4 & 118.46 & 118.41 \\
\hline C5-C4-F14 & 118.3 & 119.30 & 119.26 \\
\hline $\mathrm{C} 1-\mathrm{O} 7-\mathrm{C} 8$ & 115.9 & 116.30 & 116.66 \\
\hline
\end{tabular}

Table II. Theoretically computed thermodynamic parameters of 2,4-difluoroanisole

\begin{tabular}{|c|c|c|}
\hline Parameter & $\mathrm{HF}$ & B3LYP \\
\hline \multirow[t]{2}{*}{ Zero-point vibrational Energy $(\mathrm{kJ} / \mathrm{mol}$} & 326.134 & 303.599 \\
\hline & 2.77732 & 2.78420 \\
\hline \multirow{2}{*}{ Rotational constants $(\mathrm{GHz})$} & 0.93582 & 0.91108 \\
\hline & 0.73099 & 0.71184 \\
\hline \multicolumn{3}{|l|}{ Thermal energy $(\mathrm{kJ} / \mathrm{mol})$} \\
\hline Total & 83.096 & 78.097 \\
\hline Translational & 0.889 & 0.889 \\
\hline Rotational & 0.889 & 0.889 \\
\hline Vibrational & 81.318 & 76.320 \\
\hline \multicolumn{3}{|c|}{ Heat capacity at constant volume $\left(\mathrm{calmol}^{-1} \mathrm{Kelvin}^{-1}\right)$} \\
\hline Total & 30.177 & 32.592 \\
\hline Translational & 2.981 & 2.981 \\
\hline Rotational & 2.981 & 2.981 \\
\hline Vibrational & 24.215 & 26.630 \\
\hline \multicolumn{3}{|l|}{ Entropy $\left(\right.$ calmol $^{-1}$ Kelvin $\left.^{-1}\right)$} \\
\hline Total & & 92.880 \\
\hline $\begin{array}{l}\text { Published By: } \\
\text { Blue Eyes Intelligence Engineering } \\
\text { \& Sciences Publication }\end{array}$ & & \\
\hline
\end{tabular}




\begin{tabular}{ccc}
\hline Translational & 40.806 & 40.806 \\
Rotational & 29.516 & 29.516 \\
Vibrational & 19.637 & 22.508 \\
Dipole moment $\mu_{\text {total }}$ (Debye) & 2.0675 & 1.8078 \\
\hline
\end{tabular}

Table III. FTIR, Raman and calculated (unscaled and scaled) vibrational frequencies $\left(\mathrm{cm}^{-1}\right)$, IR intensity $\left(\mathrm{km} \mathrm{mol}^{-1}\right)$,

\begin{tabular}{|c|c|c|c|c|c|c|c|c|c|c|c|c|}
\hline \multirow[b]{2}{*}{ No } & \multirow{2}{*}{$\begin{array}{l}\text { Symm. } \\
\text { Species }\end{array}$} & \multicolumn{2}{|c|}{$\begin{array}{l}\text { Experimental } \\
\text { frequencies }\end{array}$} & \multicolumn{4}{|c|}{$\mathrm{HF} 6-311++\mathrm{G}(\mathrm{d}, \mathrm{p})$} & \multicolumn{4}{|c|}{ B3LYP $6-311++\mathrm{G}(\mathrm{d}, \mathrm{p})$} & \multirow{2}{*}{$\begin{array}{l}\text { Characterizati } \\
\text { on of normal } \\
\text { modes with } \\
\text { PED }(\%)\end{array}$} \\
\hline & & FTIR & $\begin{array}{c}\text { FT-Ra } \\
\text { man }\end{array}$ & $\begin{array}{l}\text { Un } \\
\text { Scaled }\end{array}$ & Scaled & $\begin{array}{c}\mathrm{IR} \\
\text { intensity }\end{array}$ & $\begin{array}{l}\text { Raman } \\
\text { activity }\end{array}$ & $\begin{array}{l}\text { Un } \\
\text { Scaled }\end{array}$ & Scaled & $\begin{array}{c}\mathrm{IR} \\
\text { intensity }\end{array}$ & $\begin{array}{l}\text { Raman } \\
\text { activity }\end{array}$ & \\
\hline 1 & $\mathrm{~A}^{\prime}$ & 3087 & - & 3374 & 3099 & 0.20 & 16.96 & 3215 & 3093 & 0.80 & 11.35 & $\mathrm{CH}(100)$ \\
\hline 2 & $\mathrm{~A}^{\prime}$ & - & 3084 & 3368 & 3095 & 1.32 & 21.91 & 3210 & 3088 & 0.52 & 22.1 & $\mathrm{CH}(100)$ \\
\hline 3 & $\mathrm{~A}^{\prime}$ & 3013 & - & 3350 & 3029 & 3.54 & 8.28 & 3194 & 3016 & 2.03 & 31.2 & $\mathrm{CH}(100)$ \\
\hline 4 & $\mathrm{~A}^{\prime}$ & 2964 & - & 3285 & 2983 & 37.33 & 6.98 & 3138 & 2969 & 18.33 & 13.62 & $\mathrm{CH}_{3}$ ips (98) \\
\hline 5 & $\mathrm{~A}^{\prime}$ & - & 2934 & 3240 & 2951 & 36.21 & 7.07 & 3095 & 2937 & 25.89 & 15.55 & $\mathrm{CH}_{3} \mathrm{ss}(98)$ \\
\hline 6 & $\mathrm{~A}^{\prime \prime}$ & 2844 & 2837 & 3170 & 2862 & 55.08 & 11.5 & 3020 & 2840 & 57.32 & 23.92 & $\mathrm{CH}_{3}$ ops (97) \\
\hline 7 & $\mathrm{~A}^{\prime}$ & 1606 & - & 1815 & 1625 & 24.03 & 10.66 & 1653 & 1610 & 14.47 & 75.22 & $\mathrm{CC}(89)$ \\
\hline 8 & $\mathrm{~A}^{\prime}$ & 1516 & - & 1787 & 1532 & 57.21 & 8.14 & 1634 & 1521 & 34.55 & 25.63 & $\mathrm{CC}(87)$ \\
\hline 9 & $\mathrm{~A}^{\prime}$ & 1466 & - & 1685 & 1481 & 357.85 & 1.4 & 1534 & 1470 & 305.93 & 10.13 & $\mathrm{CH}_{3}$ ipb (87) \\
\hline 10 & $\mathrm{~A}^{\prime}$ & 1445 & - & 1626 & 1465 & 9.22 & 6.97 & 1507 & 1449 & 13.06 & 27.24 & $\mathrm{CC}(84)$ \\
\hline 11 & $\mathrm{~A}^{\prime}$ & 1401 & - & 1617 & 1420 & 6.04 & 10.24 & 1491 & 1405 & 5.38 & 3.02 & $\mathrm{CC}(81), \mathrm{bCH}(14)$ \\
\hline 12 & $\mathrm{~A}^{\prime}$ & 1318 & - & 1603 & 1331 & 21.06 & 2.01 & 1474 & 1321 & 19.28 & 3.5 & CC (82), Rasymd (17) \\
\hline 13 & $\mathrm{~A}^{\prime}$ & - & 1311 & 1577 & 1325 & 25.30 & 2.81 & 1450 & 1316 & 14.36 & 10.21 & $\mathrm{CH}_{3} \mathrm{sb}(80)$ \\
\hline 14 & $\mathrm{~A}^{\prime}$ & 1298 & - & 1443 & 1317 & 52.85 & 37.26 & 1324 & 1303 & 36.70 & 1.53 & $\mathrm{CF}(88)$ \\
\hline 15 & $\mathrm{~A}^{\prime}$ & - & 1292 & 1390 & 1310 & 138.04 & 1.72 & 1309 & 1298 & 26.92 & 17.92 & $\begin{array}{l}\text { Rtrigd (73), Rsymd } \\
\text { (21) }\end{array}$ \\
\hline 16 & $\mathrm{~A}^{\prime}$ & 1286 & - & 1346 & 1299 & 33.15 & 2.65 & 1268 & 1290 & 92.81 & 2.28 & $\mathrm{CO}(82)$ \\
\hline 17 & $\mathrm{~A}^{\prime}$ & - & 1279 & 1302 & 1291 & 41.32 & 4.43 & 1232 & 1283 & 70.96 & 5.49 & Rasymd (74), $\mathrm{CH}$ (18) \\
\hline 18 & $\mathrm{~A}^{\prime}$ & 1261 & - & 1281 & 1273 & 55.49 & 1.94 & 1194 & 1266 & 35.11 & 5.38 & CC (79), Rasymd (20) \\
\hline 19 & $\mathrm{~A}^{\prime}$ & 1219 & - & 1277 & 1231 & 44.80 & 2.52 & 1169 & 1224 & 1.56 & 7.8 & $\mathrm{CF}(87)$ \\
\hline 20 & $\mathrm{~A}^{\prime}$ & 1183 & - & 1218 & 1196 & 20.53 & 4.28 & 1151 & 1187 & 67.37 & 28.17 & $\mathrm{bCH}(70), \mathrm{CC}(23)$ \\
\hline 21 & $\mathrm{~A}^{\prime \prime}$ & 1143 & - & 1183 & 1153 & 10.33 & 2.84 & 1110 & 1140 & 31.99 & 2.5 & $\mathrm{CH}_{3} \mathrm{opb}(69)$ \\
\hline 22 & $\mathrm{~A}^{\prime}$ & - & 1119 & 1143 & 1131 & 113.58 & 15.12 & 1027 & 1113 & 81.55 & 2.56 & $\begin{array}{l}\text { Rsymd (73), Rasymd } \\
(21)\end{array}$ \\
\hline 23 & $\mathrm{~A}^{\prime}$ & 1106 & - & 1072 & 1121 & 0.38 & 0.08 & 973 & 1111 & 70.18 & 11.16 & $\mathrm{O}-\mathrm{CH}_{3}(75)$ \\
\hline 24 & $\mathrm{~A}^{\prime}$ & - & 1099 & 1051 & 1110 & 56.44 & 16.94 & 951 & 1094 & 2.64 & 56.3 & $\mathrm{CH}_{3} \mathrm{ipr}(68)$ \\
\hline 25 & $\mathrm{~A}^{\prime}$ & 1031 & - & 973 & 1052 & 52.87 & 0.11 & 864 & 1036 & 49.09 & 1.38 & bCH (69), $\mathrm{CH}$ (19) \\
\hline 26 & $\mathrm{~A}^{\prime \prime}$ & - & 963 & 936 & 982 & 22.78 & 0.51 & 834 & 969 & 15.81 & 0.04 & $\mathrm{CH}_{3}$ opr (70) \\
\hline 27 & $\mathrm{~A}^{\prime}$ & - & 955 & 840 & 971 & 23.49 & 38.98 & 766 & 959 & 25.06 & 2.28 & $\mathrm{bCH}(67), \mathrm{CC}(23)$ \\
\hline 28 & $\mathrm{~A}^{\prime \prime}$ & 862 & - & 810 & 872 & 3.93 & 35.11 & 736 & 865 & 18.59 & 1.65 & $\omega \mathrm{CH}(59)$ \\
\hline 29 & $\mathrm{~A}^{\prime \prime}$ & 801 & - & 786 & 810 & 23.71 & 11.46 & 715 & 804 & 7.65 & 1.85 & $\omega \mathrm{CH}(53)$ \\
\hline 30 & $\mathrm{~A}^{\prime \prime}$ & 754 & 761 & 690 & 769 & 11.16 & 4.79 & 618 & 759 & 10.14 & 1.67 & $\omega \mathrm{CH}(51)$ \\
\hline 31 & $\mathrm{~A}^{\prime \prime}$ & 718 & 711 & 641 & 731 & 8.48 & 24.47 & 592 & 715 & 5.76 & 40.54 & tRsym (59), $\omega \mathrm{CH}(21)$ \\
\hline 32 & $\mathrm{~A}^{\prime \prime}$ & 598 & 602 & 567 & 613 & 3.08 & 10.24 & 521 & 600 & 2.42 & 4.32 & tRtrig (57), tRaysm \\
\hline 33 & $\mathrm{~A}^{\prime}$ & 505 & 502 & 546 & 524 & 2.70 & 12.94 & 492 & 504 & 2.67 & 26.85 & b O- $\mathrm{CH}_{3}(75)$ \\
\hline 34 & $\mathrm{~A}^{\prime \prime}$ & 498 & - & 497 & 519 & 3.59 & 6.23 & 454 & 503 & 3.83 & 7.49 & $\begin{array}{l}\text { tRaysm (53), } \omega \mathrm{CO} \\
(21)\end{array}$ \\
\hline 35 & $\mathrm{~A}^{\prime}$ & 493 & - & 444 & 510 & 2.18 & 24.59 & 404 & 498 & 2.40 & 21.6 & bCF (67), CC (23) \\
\hline 36 & $\mathrm{~A}^{\prime \prime}$ & 466 & - & 368 & 479 & 6.69 & 0.57 & 339 & 470 & 4.31 & 2.35 & $\begin{array}{l}\omega \mathrm{O}-\mathrm{CH}_{3}(65), \mathrm{CO} \\
\text { (19) }\end{array}$ \\
\hline 37 & $\mathrm{~A}^{\prime}$ & - & 379 & 333 & 392 & 0.31 & 5.24 & 305 & 384 & 0.14 & 11.34 & $\mathrm{bCF}(64), \mathrm{CC}(27)$ \\
\hline 38 & $\mathrm{~A}^{\prime}$ & - & 371 & 269 & 383 & 2.64 & 27.49 & 238 & 376 & 3.16 & 6.45 & $\begin{array}{l}\text { bCO (59), Rsymd } \\
\text { (23) }\end{array}$ \\
\hline 39 & $\mathrm{~A}^{\prime \prime}$ & - & 301 & 252 & 316 & 1.91 & 29.5 & 234 & 308 & 1.91 & 26.39 & $\omega \mathrm{CF}(59), \omega \mathrm{CO}(19)$ \\
\hline 40 & $\mathrm{~A}^{\prime \prime}$ & - & 233 & 170 & 246 & 0.62 & 1.68 & 163 & 230 & 2.12 & 31.16 & $\omega \mathrm{CF}(53)$, tRaysm (23) \\
\hline 41 & $\mathrm{~A}^{\prime \prime}$ & - & 150 & 122 & 168 & 1.19 & 50.97 & 112 & 153 & 0.59 & 28.72 & $\begin{array}{l}\omega \mathrm{CO}(54), \omega \mathrm{O}-\mathrm{CH}_{3} \\
(21)\end{array}$ \\
\hline 42 & $\mathrm{~A}^{\prime \prime}$ & - & 112 & 77 & 130 & 4.21 & 100 & 51 & 116 & 3.76 & 100 & $\tau \mathrm{CH}_{3}(61)$ \\
\hline
\end{tabular}

Raman activity $\left(\AA^{4} \mathrm{amu}^{-1}\right)$, and vibrational assignments of 2,4-difluoroanisole

$1465,1420,1331,1273$ by HF method and at 1610,1521 , $1449,1405,1321,1266 \mathrm{~cm}^{-1}$ by B3LYP method, employing

\section{C-C Vibrations}

The spectral region ranging between 1600 and $1400 \mathrm{~cm}^{-1}$, there are characteristic bands of $\mathrm{C}-\mathrm{C}$ aromatic stretching vibrations have been studied in both the observed IR and Raman spectra [15]. In DFA, IR active bands at 1606 , $1516,1445,1401,1318$ and $1261 \mathrm{~cm}^{-1}$ have been allocated to C-C stretching modes and they are computed at 1625, 1532, $6-311++\mathrm{G}(\mathrm{d}, \mathrm{p})$ basis set. Similarly, the observed bands for in-plane and out-of-plane bending modes are in concurrence with the estimated ones as given in Table III. 


\section{C-F Vibrations}

The vibrations associated with $\mathrm{C}-\mathrm{X}(\mathrm{X}=\mathrm{F}, \mathrm{Cl}, \mathrm{Br})$ bonds formed between the ring and the halogen atoms are important to discuss, since the presence of heavy atoms and lowering of molecular symmetry may yield mixed vibrations [16]. The absorption takes place in DFA, the IR bands at 1298 and $1219 \mathrm{~cm}^{-1}$ and computed at 1317, 1231, 1303 and $1224 \mathrm{~cm}^{-1}$ have been allocated to the mode $\mathrm{C}-\mathrm{F}$ stretching vibrations. Also, IR and Raman bands (493 and $379 \mathrm{~cm}^{-1}$ )and Raman bands(301, $233 \mathrm{~cm}^{-1}$ )are assigned to $\mathrm{C}-\mathrm{F}$ in-plane and out-of-plane bending mode, respectively. The consistency with the analyzed wavenumbers is revealed in Table III.

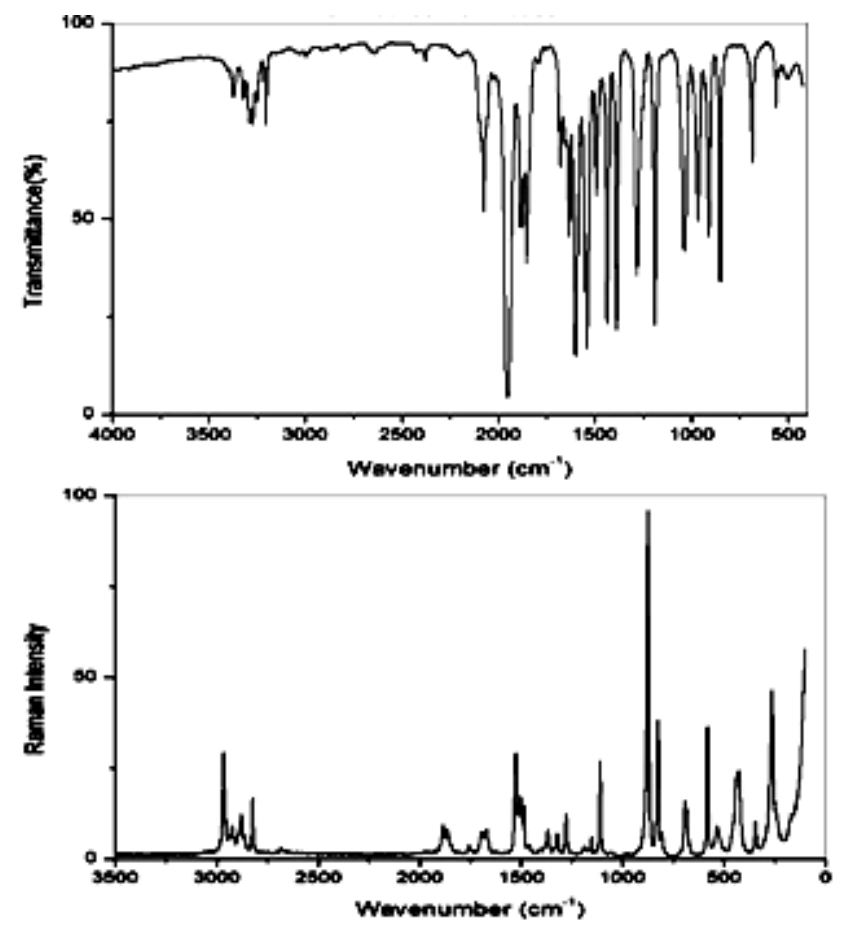

Figure 2. FTIR and FT-Raman spectra of 2,4-difluoroanisole

\section{Methyl Group Vibrations}

There are nine fundamental modes associated with each methyl group, out of which 5 modes are in-plane (A') and the remaining 4 modes are out-of-plane and are predictable as depolarized for symmetry class A". At lower frequencies, the stretching in $\mathrm{CH}_{3}$ occurs than those of aromatic ring (3000-3100 $\mathrm{cm}^{-1}$ ). Around $2980 \mathrm{~cm}^{-1}$, asymmetric $\mathrm{CH}_{3}$ stretching mode and $2870 \mathrm{~cm}^{-1}$ corresponds to symmetric one is expected in the region of $\mathrm{CH}_{3}$ group [17]. The asymmetric stretching frequency of $-\mathrm{CH}_{3}$ is allocated at $2964 \mathrm{~cm}^{-1}$, for which $2983 \mathrm{~cm}^{-1}$ and $2969 \mathrm{~cm}^{-1}$ are $\mathrm{HF}$ and the B3LYP computed wave numbers, respectively. 2934 $\mathrm{cm}^{-1}$ Raman band in DFA is assigned to $-\mathrm{CH}_{3}$ symmetric stretching for which the computed wave numbers are 2951 and $2937 \mathrm{~cm}^{-1}$. The $\mathrm{CH}_{3}$ out-of-plane stretching under $\mathrm{A}^{\prime \prime}$ species are computed at 2862, $2840 \mathrm{~cm}^{-1}$ and observed at 2844, $2837 \mathrm{~cm}^{-1}$ in DFA. Good accordance between observed and calculated values of out-of-plane bending modes and rocking modes (in-plane and out-of-plane) are exhibited in Table III.

\section{NPA Charge Distribution Analysis}

Molecule's NPA Charge distribution plays vital role in the vibrational spectra and hence the NPA charge distributions of DFA were designed by HF/6-311++G(d,p) and B3LYP/6-311++G(d,p) methods and jointly presented in Table IV.

Table IV. Charge analysis for 2,4-difluoroanisole

\begin{tabular}{ccc}
\hline \multirow{2}{*}{ ATOM } & \multicolumn{2}{c}{ NPA charges } \\
\cline { 2 - 3 } & HF & B3LYP \\
\hline C1 & 0.25125 & 0.23775 \\
C2 & 0.44749 & 0.38557 \\
C3 & -0.32588 & -0.31852 \\
C4 & 0.47193 & 0.41138 \\
C5 & -0.27617 & -0.27034 \\
C6 & -0.17439 & -0.20247 \\
O7 & -0.62704 & -0.56469 \\
C8 & -0.08518 & -0.19845 \\
H9 & 0.14632 & 0.17815 \\
H10 & 0.16048 & 0.18721 \\
H11 & 0.13727 & 0.16569 \\
F12 & -0.38382 & -0.34838 \\
H13 & 0.22588 & 0.23884 \\
F14 & -0.38860 & -0.35072 \\
H15 & 0.21332 & 0.22626 \\
H16 & 0.20714 & 0.22273 \\
\hline
\end{tabular}

From the NPA values listed in Table IV, we have examined the presence of electropositivenature in all hydrogen atoms and electronegative in all oxygen as well as fluorine atoms in DFA. The electro-positive as well as electro-negative scenario in carbon atoms depends upon the nature of atoms bonded with them. For example, C2 and C4 atoms in DFA are exhibiting strong electro positive nature since the strong electronegative fluorine atoms are bonded to it.

\section{NMR Chemical Shifts}

The reactive organic as well as ionic species identification was often done by isotropic chemical shifts [18]. Optimized geometry using B3LYP/6-311++G(d,p) method has been made by the Gauge-including atomic orbital (GIAO) ${ }^{1} \mathrm{H}$ and ${ }^{13} \mathrm{C}$ chemical shift calculations of the title compound and the results are presented in Table V. For DFA, the $\mathrm{C}-\mathrm{H}$ protons chemical shifts are in the range 4.01-7.82 ppm. Among the $\mathrm{C}-\mathrm{H}$ protons, the methyl protons are most deshielded and hence they have lower chemical shifts compared with other protons in the title compound. Usually, the typical range of ${ }^{13} \mathrm{C}$ NMR chemical shift in organic molecules is greater than the value of $100 \mathrm{ppm}$ [19]. In Table $\mathrm{V}$, the chemical shifts of carbon atoms are ranging from the values $78.43 \mathrm{ppm}$ to $184.41 \mathrm{ppm}$. The carbon atoms attached to fluorine atoms F12 and F14 are found to be most deshielded and the carbon atom C8 (methyl group) is most shielded and hence it has the least chemical shift in the value $78.43 \mathrm{ppm}$. 
Table V. The chemical shielding and shift (GIAO method) for 2,4-difluoroanisole

\begin{tabular}{cccc}
\hline ATOM & $\begin{array}{c}\text { Chemical } \\
\text { shift }(\mathrm{ppm})\end{array}$ & ATOM & $\begin{array}{c}\text { Chemical } \\
\text { shift }(\mathrm{ppm})\end{array}$ \\
\hline H9 & 5.08 & C1 & 168.62 \\
H10 & 4.56 & C2 & 182.76 \\
H11 & 4.01 & C3 & 126.2 \\
H13 & 7.54 & C4 & 184.41 \\
H15 & 7.51 & C5 & 132.67 \\
H16 & 7.82 & C6 & 146.17 \\
& & C8 & 78.43 \\
\hline
\end{tabular}

\section{E. HOMO-LUMO Analysis}
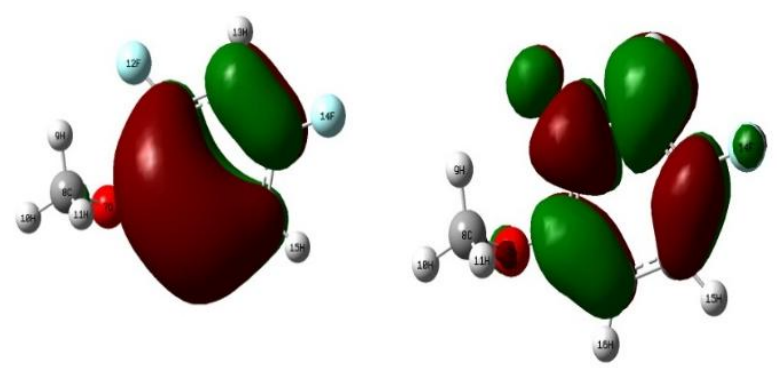

Номо

LUMO

Figure 3. HOMO-LUMO of 2,4-difluoroanisole

The significant features of a molecule is decided by the highest occupied molecular orbital (HOMO), lowest unoccupied molecular orbital (LUMO) and the energy gap between them [20]. In recent research, the energy gap laid by HOMO and LUMO has been utilized to demonstrate the bioactivity from intra-molecular charge transfer (ICT) [21]. The molecular orbital (MO) calculations indicate that the title compound DFA has 37 occupied MOs. The energies of HOMO and LUMO, their orbital energy gap iscalculated using the B3LYP/6-311++G(d,p)method. The HOMO-LUMO energy gap is found to be $7.4909 \mathrm{eV}$. The frontier molecular orbitals of DFA are shown in Fig. 3.

\section{F. NBO Analysis}

NBO (Natural Bond Orbital) analyses explain the intra and inter molecular bonding strength and bond interaction [22]. In Table VI, the perturbation energies of significant donor-acceptor interactions are presented for DFA. The strong interaction between electron donors and acceptors can be understood by the larger value of interaction energy, $\mathrm{E}(2)$. The intermolecular interaction between BD (2) C1 - C6 $\rightarrow \mathrm{BD}^{*}$ (2) $\mathrm{C} 2-\mathrm{C} 3$ has been recognized as the interaction giving the strongest stabilization to the system since it has higher second order perturbation energy of the order of 22.79 $\mathrm{kcal} / \mathrm{mol}$. Further, the interactions initiated by lone pair parent NBOs like LP (2) O7 $\rightarrow \mathrm{BD}^{*}$ (2) C1 - C6, LP (3) F12 $\rightarrow \mathrm{BD}^{*}(2) \mathrm{C} 2-\mathrm{C} 3$ and $\mathrm{LP}$ (3) F14 $\rightarrow \mathrm{BD}^{*}$ (2) $\mathrm{C} 4-\mathrm{C} 5$ are giving reasonable amount of stabilization because of their higher $\mathrm{E}(2)$ value.
Table VI. Significant donor - acceptor interactions in 2,4-difluoroanisole

\begin{tabular}{|c|c|c|c|c|}
\hline $\begin{array}{l}\text { Donor NBO } \\
\text { (i) }\end{array}$ & $\begin{array}{l}\text { Acceptor NBO } \\
\text { (i) }\end{array}$ & $\begin{array}{c}\mathrm{E}(2) \\
(\mathrm{kcal} / \mathrm{mol})\end{array}$ & $\begin{array}{l}\left(E_{j}-E_{i}\right) \\
\text { (a.u) }\end{array}$ & $\begin{array}{l}F(i, j) \\
\text { (a.u) }\end{array}$ \\
\hline $\mathrm{BD}(2) \mathrm{C} 1-$ & $\mathrm{BD}^{*}(2) \mathrm{C} 2-\mathrm{C} 3$ & 22.79 & 0.28 & 0.072 \\
\hline C6 & $\mathrm{BD}^{*}(2) \mathrm{C} 4-\mathrm{C} 5$ & 18.57 & 0.28 & 0.065 \\
\hline $\mathrm{BD}(2) \mathrm{C} 2-$ & $\mathrm{BD}^{*}$ (2) $\mathrm{C} 1-\mathrm{C} 6$ & 17.56 & 0.30 & 0.066 \\
\hline $\mathrm{C} 3$ & $\mathrm{BD}^{*}(2) \mathrm{C} 4-\mathrm{C} 5$ & 21.28 & 0.30 & 0.072 \\
\hline $\mathrm{BD}(2) \mathrm{C} 4-$ & $\mathrm{BD}^{*}$ (2) $\mathrm{C} 1-\mathrm{C} 6$ & 21.14 & 0.29 & 0.071 \\
\hline C5 & $\mathrm{BD}^{*}$ (1) $\mathrm{C} 2-\mathrm{C} 3$ & 18.90 & 0.28 & 0.066 \\
\hline LP (2) O7 & $\mathrm{BD}^{*}$ (2) $\mathrm{C} 1-\mathrm{C} 6$ & 10.64 & 0.37 & 0.061 \\
\hline LP(3) F12 & $\mathrm{BD}^{*}(2) \mathrm{C} 2-\mathrm{C} 3$ & 17.92 & 0.43 & 0.086 \\
\hline LP(3) F14 & $\mathrm{BD}^{*}(2) \mathrm{C} 4-\mathrm{C} 5$ & 17.98 & 0.43 & 0.086 \\
\hline
\end{tabular}

\section{CONCLUSION}

The optimized structure of 2,4-difluoroanisole(DFA) has been acquired and the bond length/bond angles are computed. The calculated geometric parameters are in good concurrence with the experimental values. The precisely assigned vibrational frequencies from the recorded FT-IR/ FT-Raman spectra for the fundamental modes of DFA are in concurrence with the calculated results. The NMRchemical shifts for hydrogen and carbon atoms have been calculated. The charge distribution on the molecule was furnished by NPA analysis. The energy gap of HOMO-LUMO and the second order perturbation energy calculations explains the eventual charge transfer interaction that occurs inside the molecule, which influences the spectral and biological activities of the molecule.

\section{REFERENCES}

1. V. Krishnakumar, and N. Prabavathi, "Simulation of IR and Raman spectra of p-hydroxyanisole and p-nitroanisole based on scaled DFT force fields and their vibrational assignments," Spectrochim. Acta A Mol. Biomol. Spectrosc., vol. 74 , 2009, pp. 154-161.

2. Ramalingam, and S. Periandy, "Spectroscopic investigation, computed IR intensity, Raman activity and vibrational frequency analysis on 3-bromoanisole using $\mathrm{HF}$ and DFT (LSDA/MPW1PW91) calculations," Spectrochim. Acta A Mol. Biomol. Spectrosc., vol. 78, 2011, pp. 835-843.

3. T. Prabhu, S. Periandy, and S. Ramalingam, "FT-IR and FT-Raman spectroscopic investigation, computed vibrational frequency analysis and IR intensity and Raman activity peak resemblance analysis on 2-nitroanisole using HF and DFT (B3LYP and B3PW91) calculations," Spectrochim. Acta A Mol. Biomol. Spectrosc., vol. 83, 2011, pp. 8-16.

4. M. Arivazhagan, and S. Prabhakaran, "DFT studies and vibrational spectra of 2-bromomethyl-4-nitroanisole," Indian J. Pure \& Appl. Phys., vol.50, 2012, pp.26-33.

5. H.J. Frisch, G.W. Trucks, H.B. Schlegel, G.E. Scuseria, M.A. Robb, J.R. Cheeseman, H.Nakatsuji, M. Caricato, X. Li, H.P. Hratchian, K. Toyota, R. Fukuda, J.Hasegawa, M. Ishida, R. Nakajima, Y. Honda, O. Kilao, H. Nakai, T. Verven, J. A. Montgomery Jr., J.E. Peralta, F. Ogliaro, M. Bearpark, J. J. Heyd, E. Brothers, K. N. Kudin, V.N. Staroveror, R. Kobayashi, J. Normand, K. Ragavachari, A. Rendell, J.C. Burant, S. J. Tomasi, M. Cossi, N. Rega, J. M. Millam, M. Klene, J. E. Knox, J. B. Cross, V. Bakken, C. Adamo, J. Jaramillo, R. Gomperts, R.E. Strattmann, O. Yazyev, A.J. Austin, R. Cammi, J.W. Ochetrski, R.L. Martin, K. Morokuma, V.G. Zakrazawski, G.A.Votn, P. Salvador, J.J. Dannenberg, S. Dapprich, A.D. Daniels, O. Farkas and J.B. Foresman, Gaussian O.G., Revision A.O2, Gaussian Inc., Wallingford, CT. 2009.

6. A. D. Becke, "Density-functional thermochemistry. III. The role of exact exchange," J. Chem. Phys., vol. 98, 1993, pp. 5648 - 5652.

7. C. Lee, W. Yang and R.G. Parr, "Development of the Colic-Salvetti correlation-energy formula into a functional of the electron density," Phys. Rev. B., vol. 37, 1988, pp. 785-789. 
8. G. Rahut and R. Pulay, "Transferable Scaling Factors for Density Functional Derived Vibrational Force Fields," J. Phys. Chem., vol. 99, 1994, pp. 3093-3100, 1994

9. T. Sundius, Scaling of ab initio force fields by MOLVIB, Vib. Spectrosc., vol. 29, 2002, pp. 89-95.

10. N.I. Giricheva, G.V. Girichev, J.S. Levina, and H. Oberhammer, "Molecular structures and conformations of 4-fluoranisole and 3,4-difluoranisole: gas electron diffraction and quantum chemical calculations, J. Mol. Struct.," vol. 703, pp. 55-62, 2004.

11. L. Zhang, C. Dong, M. Cheng, L. Hu, Y. Du, Q. Zhu, and C. Zhang, "Resonance-enhanced two-photon ionization spectroscopy and theoretical calculations of 3,5-difluoroanisole and its Ar-containing complex," Spectrochim. Acta A Mol. Biomol. Spectrosc., vol. 96, 2012, pp. 578-585.

12. M. Karaback, M. Cinar, and M. Kurt, "An experimental and theoretical study of molecular structure and vibrational spectra of 2 -chloronicotinic acid by density functional theory and ab initio Hartree-Fock calculations," J. Mol. Struct., vol. 885, 2008, pp. $28-35$.

13. G. Varsanyi, Assignments for Vibrational Spectra of Seven Hundred Benzene Derivations, vol. 1, 1974, Adam Hilger, London.

14. G. Socrates, Infrared and Raman Characteristic Group Frequencies, Tables and Charts, 3rd ed., 2001, Wiley, Chichester.

15. V. Krishnakumar, and R.J. Xavier, "Molecular and vibrational structure of 2-mercapto pyrimidine and 2,4-diamino-6-hydroxy-5-nitroso pyrimidine: FT-IR, FT-Raman and quantum chemical calculations," Spectrochim. Acta A Mol. Biomol. Spectrosc., vol. 63, 2006, pp. 454-463.

16. R. J. Xavier, and E. Gobinath, "Experimental and theoretical spectroscopic studies, HOMO-LUMO, NBO and NLMO analysis of 3,5-dibromo-2,6-dimethoxy pyridine," Spectrochim. Acta A Mol. Biomol. Spectrosc., vol. 97, 2012, pp. 215-222.

17. M. T. Güllüoglu, M. Özduran, M. Kurt, S. Kalaichelvan, and N. Sundaraganesan, "Molecular structure and vibrational spectra of 2and 5-methylbenzimidazole molecules by density functional theory," Spectrochim. Acta A Mol. Biomol. Spectrosc., vol. 76, 2010, pp. 107-114.

18. S. Sebastian, N. Sundaraganesan, B. Karthikeyan, and V. Srinivasan, "Quantum mechanical study of the structure and spectroscopic (FT-IR, FT-Raman, 13C, 1H and UV), first order hyperpolarizabilities, NBO and TD-DFT analysis of the 4-methyl-2-cyanobiphenyl," Spectrochim. Acta A Mol. Biomol. Spectrosc., vol.78, 2011, pp. 590-600.

19. K. Pihlager, E. Kleinpeter (Eds), Carbon ${ }^{13}$ Chemical shifts in structure and Spectrochimical analysis, VCH publishers, Deerfiled Beach, 1994.

20. M. Amalanathan, V.K. Rastogi, I.H. Joe, M.A. Palafox, and R. Tomar, Density functional theory calculations and vibrational spectral analysis of 3,5-(dinitrobenzoic acid), Spectrochim. Acta, vol. A78, 2011, pp.1437- 1444 .

21. L. Padmaja, C. Ravi Kumar, D. Sajan, I.H. Joe, V.S. Jayakumar, and G.R. Pettit, Density functional study on the structural conformations and intramolecular charge transfer from the vibrational spectra of the anticancer drug combretastatin-A2, J. Raman Spect., vol. 40, 2009 pp. $419-428$.

22. A.E. Reed, L.A. Curtiss, and F. Weinhold, Intermolecular interactions from a natural bond orbital, donor-acceptor viewpoint, Chem. Rev., vol. 88,1988, pp. 899-926.

\section{AUTHORS PROFILE}

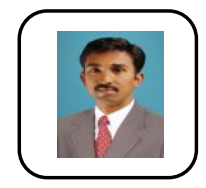

S. Jeyavijayan has completed M.Sc. and Ph.D. from Bharathidasan University, Trichirappalli in 2014. Currently working as Assistant Professor in the Department of Physics, Kalasalingam Academy of Research and Education and published more than 25 papers in National and International Journals. His fields of interest are Molecular Spectroscopy and Theoretical and Computational chemistry.

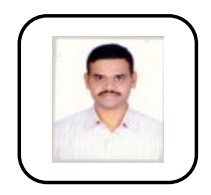

Palani Murugan has completed M.Sc from Bharathiar University, Coimbatore and M.Phil from Bharathidasan University, Tiruchirapalli. Presently working as Lecturer, Physics, in DR.B.R.Ambedkar Institute of Technology Port Blair since June 2012. Currently pursuing Ph.D from Kalasalingam Academy of Research and Education.

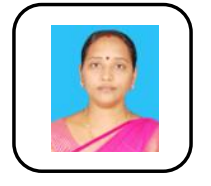

M.S.Revathy has completed her Ph.D in Anna University in 2016. She has done M.Sc., M.Phil Physics in Mother Teresa Women's University, Kodaikanal. Currently working as Assistant Professor in Department of Physics, Kalasalingam Academy of Research and Education and her field of interests are thin films and green synthesis of nanomaterials. She has published 6 papers in national and international journals.

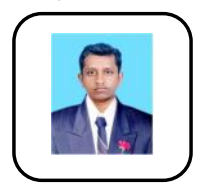

K. Gurushankar has completed M.Sc. and M.Phil., Ph.D. from Annamalai University Chidambaram in 2015 Joined as Assistant Professor at Kalasalingam University from June 2016 onwards. His fields of interest are "Applied spectroscopy in biological field". He has published 12 papers in leading International Journals.

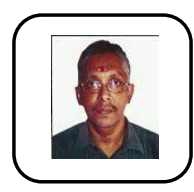

K. Viswanathan has completed M.Sc. and Ph.D. from University of Kerala Trivandrum in 1984 and worked in the High Energy Cosmic Ray group of TIFR for 22 years. Worked as Professor and HoD of Physics in Karpagam University for 10 years. Joined Kalasalingam University in August 2016 as Senior Professor. His fields of interest are molecular spectroscopy and Astroparticle physics at high energies. 